tion rather than degradation of aggregated protein is essential for thermotolerance because Hsp104 does not associate with proteolytic systems and substrates are reactivated rather than degraded after heat shock ${ }^{4}$. However, although reactivation is clearly necessary for thermotolerance in Escherichia coli, it is unclear whether it is sufficient - that is, there may be additional requirements to eliminate specific toxic aggregates to ensure cell viability. For example, in yeast, under specific circumstances in which Hsp104 and other heat shock protein levels are not elevated in response to elevated temperatures, increased levels of ubiquitin and proteasomal degradation reduce aggregation and enhance cell viability ${ }^{25}$.

Much remains to be done in understanding the recalcitrant but universally important subject of protein disaggregation. The brilliant work of Mogk and colleagues ${ }^{9}$ provides important new insights, and focuses our future atten- tion on the precise roles played by the middle region of Hsp104/ClpB and its interplay with the Hsp70/DnaK system.

\section{ACKNOWLEDGMENTS}

We thank A. Cashikar and G. Kramer for comments on the manuscript.

1. Dobson, C. M. Nature 426, 884-890 (2003).

2. Ellis, R.J. Trends Biochem. Sci. 26, 597-604 (2001).

3. Sanchez, Y. \& Lindquist, S.L. Science 248, 1112 1115 (1990).

4. Parsell, D.A., Kowal, A.S., Singer, M.A. \& Lindquist, S. Nature 372, 475-478 (1994).

5. Mogk, A. et al. EMBO J. 18, 6934-6949 (1999).

6. Queitsch, C., Hong, S.W., Vierling, E. \& Lindquist, S. Plant Cell 12, 479-492 (2000).

7. Glover, J.R. \& Lindquist, S. Cell 94, 73-82 (1998).

8. Goloubinoff, P., Mogk, A., Zvi, A.P., Tomoyasu, T. \& Bukau, B. Proc. Natl. Acad. Sci. USA 96, 13732 13737 (1999)

9. Weibezahn, J. et al. Cell 119, 653-665 (2004).

10. Sauer, R.T. et al. Cell 119, 9-18 (2004).

11. Lee, S. et al. Cell 115, 229-240 (2003).
12. Hattendorf, D.A. \& Lindquist, S.L. EMBO J. 21, 12-21 (2002).

13. Cashikar, A.G. et al. Mol. Cell 9, 751-760 (2002)

14. Zietkiewicz, S., Krzewska, J. \& Liberek, K. J. Biol. Chem. 279, 44376-44383 (2004).

15. Weibezahn, J., Schlieker, C., Bukau, B. \& Mogk, A. J. Biol. Chem. 278, 32608-32617 (2003).

16. Schlee, S., Beinker, P., Akhrymuk, A. \& Reinstein, J. J. Mol. Biol. 336, 275-285 (2004).

17. Schlieker, C. et al. Nat. Struct. Mol. Biol. 11, 607615 (2004).

18. Wang, J. et al. Structure 9, 177-184 (2001).

19. Lum, R., Tkach, J.M., Vierling, E. \& Glover, J.R. J. Biol. Chem. 279, 29139-29146 (2004).

20. Joshi, S.A., Hersch, G.L., Baker, T.A. \& Sauer, R.T. Nat. Struct. Mol. Biol. 11, 404-411 (2004).

21. Schirmer, E.C., Homann, O.R., Kowal, A.S. \& Lindquist, S. Mol. Biol. Cell 15, 2061-2072 (2004).

22. Mogk, A. et al. J. Biol. Chem. 278, 17615-17624 (2003).

23. Dougan, D.A., Reid, B.G., Horwich, A.L. \& Bukau, B. Mol. Cell 9, 673-683 (2002).

24. Shorter, J. \& Lindquist, S. Science 304, 1793-1797 (2004).

25. Friant, S., Meier, K.D. \& Riezman, H. EMBO J. 22 3783-3791 (2003)

\title{
Unraveling chromatin organization
}

The ordered compaction of DNA is essential to package it within the nucleus (for example, the DNA in a single human cell is more than two meters long). The first order of compaction, the 10-nm fiber, results from the winding of DNA around the core histone octamer. The crystal structure of this particle, the nucleosome, was first solved at a high resolution in 1997. It is composed of two copies each of the four histone subunits $2 \mathrm{~A}, 2 \mathrm{~B}, 3$ and 4 , which form a flattened disk, wrapped by 146 bp of DNA. Neighboring nucleosomes are separated by a variable length of linker DNA, which can be bound by a linker histone. When viewed in two dimensions, this level of organization has the appearance of beads on a string.

The next order of chromatin compaction has been called the 30$\mathrm{nm}$ fiber. Despite the fact that this structure was first visualized decades ago, the packing organization of nucleosomes within the 30-nm fiber is still debated. Three models have been proposed. In the first model (panel a) neighboring nucleosomes form a continuous helical solenoid, containing about six nucleosomes per turn. The linker DNA (yellow) has the same polarity and is positioned at the central axis. The 'helical ribbon' model (panel b) has the linker DNA joining adjacent particles in neighboring positions of the stacked helices; in this model the linker DNA lies in a groove between the nucleosome cores so that the nucleosomes are not as tightly packed as in the solenoid model. In the 'crossed-linker' model (panel c) the linker DNA is stretched across the central axis, so that neighboring nucleosomes are present on roughly opposite faces of the axis and in different helical stacks. Both the second and third models are known as two-start models, because they involve the linear nucleosome array alternating between two stacked helices.

From previous studies, it was known that the histone $\mathrm{H} 4$ tail is required for compaction, and that it interacts with the $\mathrm{H} 2 \mathrm{~A}$ and $\mathrm{H} 2 \mathrm{~B}$ subunits of a neighboring nucleosome. To test these packing models, Dorigo et al. (Science 306, 1571-1573; 2004) made cysteine substitutions within the $\mathrm{H} 4$ tails and $\mathrm{H} 2 \mathrm{~A} / \mathrm{H} 2 \mathrm{~B}$ so that higher order chromatin structure could be stabilized by crosslinking. Pairwise combinations of mutant $\mathrm{H} 4$ and mutant $\mathrm{H} 2 \mathrm{~A}$ or $\mathrm{H} 2 \mathrm{~B}$ were a
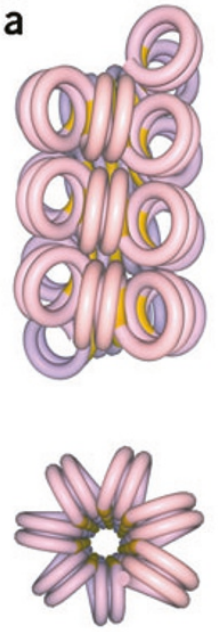

b
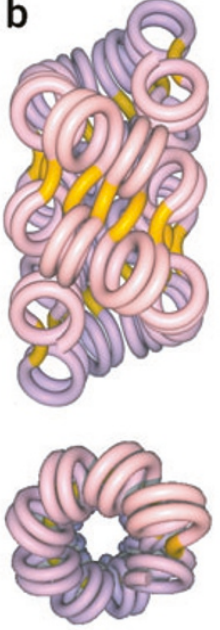

C

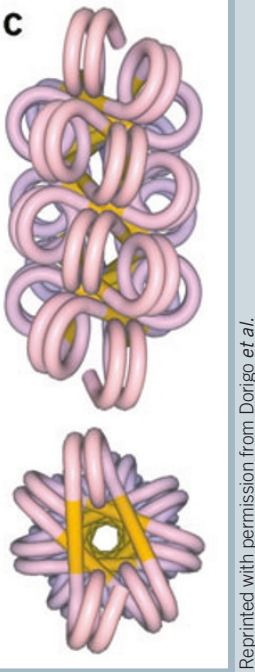

reconstituted in vitro as dodecameric nucleosome arrays, and conditions were altered to effect crosslinking and compaction. Only one mutant pair demonstrated a major crosslinked species, and this was employed to examine compaction. When linker DNA was cleaved by a restriction enzyme, the crosslinked species contained 5 or 6 nucleosomes, as would be predicted from the twostart models (panel $b$ and $c$ ), but not from the solenoid model (panel a). Next, a 48-mer array of crosslinked particles was visualized by electron microscopy to follow the path of the fiber axis. Many fibers appeared as parallel rows of particles, which dissociated into single columns of particles when the linker DNA was cleaved. This finding supports the two-start models of 30-nm fiber organization, but unfortunately leaves unresolved the question of which two-start model is correct. Higher resolution microscopy will be necessary to resolve these details.

Angela K Eggleston 